than the somewhat shadowy officials in the fluctuating divisions of the Ministry itself. Sir Sylvanus Vivian, director of registration in the First World War and registrar-general in the Second, was, in any event, one suspects, too big a man altogether to have been kept out of the centre of this picture either by Mr. Hammond or by successive generations of food rationers. His brief but compelling memorandum on a unit system of general rationing, which is printed here as an appendix and appears in essence to have anticipated the 'points' rationing system by something like a quarter of a century, reveals an imaginative grasp and a generalizing ability which, for one reason or another, were not often apparent in the schemes that followed. Those concerned with the thankless task of drawing lessons for use in the hypothetical next war might do worse than take a glance at it, if not for its matter, then for its manner. It is scarcely longer than this review.

Frank Dennill

\section{NUCLEAR MOMENTS}

\section{Kernmomente}

Von Dr. Hans Kopfermann. Zweite, neubearbeitete Auflage. Pp. xvi +463 . (Frankfurt am Main : Akademische Verlagsgesellschaft M.B.H., 1956.) 54 D. marks.

$I^{\mathrm{N}}$ $\mathrm{N}$ this second edition Dr. Hans Kopfermann has completely rewritten and greatly expanded his original book, which for fifteen years stood as a standard work in the field of optical hyperfine structure. During that time the moments of atomic nuclei in the ground state have been studied in many laboratories by the methods of high-frequency spectroscopy, which are here described in addition to the optical methods.

The first three sections of the book deal with the investigation of nuclear moments through their interactions in free atoms, free molecules and condensed phases, respectively. The fourth section gives an account of various nuclear models and compares the moments which they predict with experimental values.

The book is essentially a manual for experimenters. Thus, accounts are given of techniques in highresolution optical spectroscopy, and in work on atomic- and molecular-beam magnetic and electric resonance, nuclear magnetic and electric quadrupole resonance, and paramagnetic resonance. The methods are well illustrated with examples. The theory is given in detail, both of the various techniques and of the relations between the observed quantities and the nuclear moments themselves. References tio original papers number about four hundred. Tables are given of various correction factors, and of the moments of nuclei, their structure according to the shell model, etc.

The contents of this book reflect the wide range of activities in the laboratory which Dr. Kopfermann directs. His experience in these diverse fields enables him to give a first-hand and a balanced account of these branches of nuclear physics. Specialists will welcome the new edition as a reference book for use in their particular fields and as a text-book for instruction in kindred topics.

A consequence of the close association in the text of basic theory with the technique in which it is applied is a certain lack of continuity in the theoretical sections. I would have preferred to find the theory of the hyperfine structure of free atoms in one place, for example, rather than distributed between an introduction, a section on optical hyperfine structure and a section on atomic beam investigations. A further minor criticism is that references are not given to the sources of some of the reported measurements. These are small matters weighed against the vast amount of organized material in this book. Readers who have difficulty with the German text will welcome the English translation which is shortly to be published.

G. W. SERIES

\section{MAGIC OF THE EAST}

\section{Oriental Magic}

By Sayed Idries Shah. Pp. xviii $+206+5$ plates. (London: Rider and Company, 1956.) 25s. net.

$\mathrm{N}$ this work the author has attempted to correlate 1 the magical traditions of the East with those current in the West and to show how oriental influence was potent in moulding not only the lore of Western sorcerers but also the technique through which they claimed to produce their results. Possessed, as he is, with some ethnological training, Idries Shah is naturally interested in the similarities between beliefs and practices in different parts of the world; and thus he has made a special study of the evidence for the diffusion of culture, paying particular attention, as Blau had previously done, to the history of Egyptian magic and to that of Babylonia and Assyria. 'This book, therefore, supplies the general reader with a useful guide to the magic of the East and the importance that it must have in any appraisal of occidental sorcery.

For the purposes of the scholar, however, the book is somewhat disappointing. The author has tried to do too much in too little space, and thus much of the material is badly co-ordinated and ill-digested. In many passages he shows that he is fully aware of the difficulty of knowing what value can be placed on literary accounts of oriental miracles; yet when he has established contact with a Hindu magician who shows him striking phenomena, he does not attempt any serious investigation but takes refuge in vague suggestions of 'snap-hypnosis'. Anecdote takes the place of the kind of record we should expect from a trained ethnologist, and this is all the more regrettable since Idries Shah appears to have exjoyed opportunities for inquiry which are far from common. Nevertheless, the author stresses a point of view of which too little has been heard in the past. $\mathrm{He}$ points out how parapsychology, and, above all, the modern work on extra-sensory perception, are throwing fresh light into the dim recesses of the sorcerer's cave. Amid all the charms, the mumbo-jumbo and the hocus-pocus there may sometimes have emerged flashes of paranormal perception or even stranger things. It is here that, as the author says, the true link can be found which connects the sorcery of all ages and peoples, be they oriental or occidental.

The book is well produced and the list of authorities convenient for reference. It is surprising, however, that, although there are two references to the famous "Book of Changes", there is no discussion of the modern use of the technique in its relation to theories of psycho-kinesis.
E. J. Drngwall 